
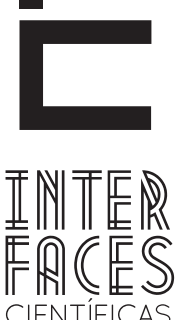

HUMANASE SOCIAIS

ISSN IMPRESSO 2316-3348

E-ISSN 2316-3801

DOI - 10.17564/2316-3801.2018v6n3p19-26

\title{
A ARQUEOLOGIA DO SABER: UMA PROPOSTA METODOLÓGICA PARA A ANÁLISE DO DISCURSO EM HISTÓRIA
}

THE ARCHAEOLOGY OF KNOWLEDGE: A METHODOLOGICAL PROPOSAL FOR DISCOURSE ANALYSIS IN HISTORY

LA ARQUEOLOGÍA DEL SABER: UNA PROPUESTA METODOLÓGICA PARA EL ANÁLISIS DEL DISCURSO EN LA HISTORIA

Roger Marcelo Martins Gomes ${ }^{1}$

\section{RESUMO}

Para além de seu tempo, a obra A Arqueologia do Saber, de Michel Foucault, permite uma reflexão sobre o método arqueológico que coloca em questão epistemologias e metodologias clássicas como a proposta pela História das Ideias. Para entender as possibilidades ofertadas pelo método arqueológico de Foucault na análise de um discurso, discute-se os conceitos e categorias fundamentais deste método. Identifica-se que o método arqueológico de Foucault dá base para a análise do discurso, desde que não se torne um a priori formal, isto é, uma camisa de força que impossibilite identificar as particularidades ou as próprias regularidades de um objeto de pesquisa.

\section{PALAVRAS-CHAVE}

Arqueologia do Saber. Metodologia. Discurso. História. 


\section{ABSTRACT}

Beyond its own time, the book "Archaeology of Knowledge", by Michel Foucault, allows a reflection on the archaeological method that calls into question epistemology and classical methodologies as proposed by the History of Ideas. To understand the possibilities offered by the archaeological method of Foucault in the analysis of a speech, this study discusses the concepts and fundamental categories of this method. It finds that the archaeological method of Foucault gi- ves basis for discourse analysis, provided it does not become a formal a priori, that is, a straitjacket that makes it impossible to identify the particularities or regularities of a research object

\section{KEYWORDS}

Archeology of knowledge. Methodology. Speech. History.

\section{RESUMEN}

Además de su tiempo, el libro "La Arqueología del Saber", Michel Foucault, permite una reflexión sobre el método arqueológico que pone en duda la epistemología y metodologías clásicas como propone la historia de las ideas. Para comprender las posibilidades que ofrece el método arqueológico de Foucault en el análisis de un discurso, discutió los conceptos y categorías fundamentales de este método. Se encuentra que el método arqueológico de Foucault da base para el análisis del discurso, ya que no llega a ser a priori formal, es decir, una camisa de fuerza que hace que sea imposible identificar los datos o propias regularidades de un objeto de la investigación.

\section{PALABRAS CLAVE}

Arqueología del Saber. Metodología. Discurso. Historia. 


\section{INTRODUÇ̃̃O}

A obra de Michel Foucault escolhida para viabilizar as discussões deste trabalho sobre metodologia é a A Arqueologia do Saber. Obra fundamental da segunda fase de seus estudos², Foucault faz consideráveis discussões acerca de conceitos clássicos como o de ciência, enunciado e saber. Ela nos permite refletir e criticar a concepção de ciência, descrição, funções enunciativas, positividade, arquivo, conceitos importantes para se entender uma determinada episteme e como descrever sobre o que Foucault define como saber/poder. Para ele, na arqueologia - como análise das regras características das diferentes práticas discursivas - encontrar-se-á o que se poderia chamar de uma teoria envolvente. (FOUCAULT, 2013, p. 249-250).

Diferentemente das obras Vigiar e Punir e A Ordem do Discurso, o texto A Arqueologia do Saber situa-se na segunda fase de Foucault, nos anos 1960, fase na qual se ocupava com a episteme e os saberes. Obra fundamental no desenvolvimento teórico de Foucault, A Arqueologia do Saber tornou-se uma proposta para uma investigação científica e uma revisão e crítica da história epistemológica. 0 propósito de Foucault com este trabalho era mostrar o local de onde ele falava, demarcar o espaço que tornava possível as suas pesquisas e da significação da palavra arqueologia.

Alguns conceitos colocados por Foucault são fecundos para realizar uma pesquisa que tem como objeto de estudo o discurso. Eis o nosso desafio neste pequeno trabalho - fazer uma breve discussão dos conceitos encontrados na obra A Arqueologia do Saber. A arqueologia proposta por Foucault é um método que contribui para um profícuo caminho na construção de uma escrita (narrativa) histórica, pode ser aplicado como um rico procedimento de pesquisa que procura descrever os discursos de diversas disciplinas.

Para Foucault devemos estudar os discursos não

\footnotetext{
2 Alguns especialistas em Foucault dividem seus estudos em quatro fases: a primeira caracterizada pelos estudos da loucura e razão definia um Foucault "heideggeriano"; a segunda fase é a arqueológica, momento em que se destacam as obras A Arqueologia do Saber e A Ordem das Coisas; a terceira caracterizada pelos estudos genealógicos marcados pela obra Vigiar e Punir e, por último, a fase do ético (PETERS, 2008, p. 16)
}

apenas em seu valor expressivo ou suas transformações formais, mas nas modalidades de sua existência: os modos de circulação, de valorização, de atribuição, de apropriação dos discursos variam de acordo com cada cultura e se modificam no interior de cada uma; a maneira com que eles se articulam nas relações sociais se decifra de modo mais direto no jogo da função autor e em suas modificações do que nos temas ou conceitos que eles operam. Trata-se de retirar do sujeito seu papel de fundamento originário e de analisá- lo como uma função variável e complexa do discurso (FOUCAULT, 2013, p. 16).

A arqueologia de Foucault descreve os discursos não para revelar verdades e continuidades, mas descrever limiares, limites, pontos de cruzamentos, controvérsias e, sobretudo, o que ele classifica de enunciados discursivos. Condição para descrever o que significa enunciado e os demais conceitos propostos por Foucault em A Arqueologia do Saber é identificar e comparar a diferença entre história epistemológica e história arqueológica.

\section{HISTÓRIA EPISTEMOLÓGICA E HISTÓRIA ARQUEOLÓGICA}

Nas diferenças entre história epistemológica e história arqueológica é importante ressaltar que a história arqueológica se desloca da ciência para o saber. Para um dos maiores estudiosos brasileiros em Foucault, Roberto Machado (2006), a arqueologia de Foucault busca ser uma crítica da ideia de racionalidade e distancia-se de qualquer tipo de ciência. A história epistemológica, por sua vez, investiga a produção da verdade pela ciência, situa-se no nível dos conceitos científicos e busca a própria racionalidade.

A história arqueológica não valoriza, segundo Machado (2006), aquilo que é normativo e regra de verdade, não busca um ordenamento temporal de encadeamento e recorrências a partir de uma racionalidade dada. Para ele, a história arqueológica estabelece inter-relações conceituais no nível do saber e ressalta: 
Parece-nos mesmo que a riqueza do método arqueológico é ser um instrumento capaz de refletir sobre as ciências do homem como saberes, neutralizando a questão de sua cientificidade e escapando ao desafio impossível de realizar, nesses casos, uma recorrência histórica, como deveria fazer uma análise epistemológica. (MACHADO, 2006, p. 9).

0 trabalho arqueológico é diferente da história epistemológica; a arqueologia não privilegia a ordem temporal de recorrências e continuidade e a questão normativa, a arqueologia está no nível do saber, na busca as controvérsias, nas práticas e nas descontinuidades. Indubitavelmente, Foucault inaugurou uma nova história, mesmo que seja ao menos em relação ao método.

[...] a história é o que transforma documentos em monumentos e que desdobra, onde se decifravam rastros deixados pelos homens, onde se tentava reconhecer em profundidade o que tinham sido, uma massa de elementos que devem ser isolados, agrupados, tornados pertinentes, inter-relacionados, organizados em conjuntos. Havia um tempo em que a arqueologia, como disciplina dos monumentos mudos, dos rastros inertes, dos objetos sem contexto e das coisas deixadas pelo passado, se voltava para a história e só tomava sentido pelo restabelecimento de um discurso histórico; que poderíamos dizer, jogando um pouco com as palavras, que a história, em nossos dias, se volta para a arqueologia - para a descrição intrínseca do monumento. (FOUCAULT, 2013, p. 8).

Foucault provocou uma ruptura sobre os métodos de se praticar e escrever História (VEYNE, 2014, p. 239). Uma forma de fazer história que considera tudo aquilo que as pessoas disseram sobre os acontecimentos. Tudo o que se diz instaura uma realidade discursiva; e, sendo o homem um ser discursivo, criado pela linguagem, a arqueologia é um método para ele se desvendar em sua própria existência (GIACOMINI; VARGAS, 2010, p. 122). Para Roger Chartier (2012, p. 38), Foucault fez uma distinção profunda sobre dois problemas confundidos pelos historiadores: "por um lado, a análise sócio-histórica do autor como indivíduo e, por outro, o problema da construção da 'função-autor', isto é, a maneira pela qual o texto aponta para essa figura".

0 primeiro passo para se entender esta proposta de Foucault é situar os discursos como uma dispersão formados por elementos que não estão ligados por nenhum princípio de unidade (BRANDÃO, 2012, p. 32). Os elementos que compõem o discurso são denominados por "regras de formação", segundo Foucault (2013), são os objetos que aparecem num "espaço comum", os conceitos em suas formas de surgimento em um campo discursivo e os temas e teorias, um sistema de relações entre diversas estratégias para dar conta de uma formação discursiva.

A arqueologia não assume o caráter de uma ciência, seu horizonte não é o de uma racionalidade histórica, buscando encontrar a inteligibilidade entre os acontecimentos (RAGUSA, 2011, p. 2731). Na pesquisa arqueológica as análises estão longe de buscar a verdade e continuidade, estão centradas no homem, na constituição histórica das ciências do homem na modernidade.

[...] a arqueologia realiza uma história dos saberes de onde desaparece qualquer traço de uma história do progresso ou da razão [...] 0 que não significa como veremos abandonar a exigência de uma análise conceitual capaz de estabelecer descontinuidades, certamente não epistemológicas, mas arqueológicas, isto é, situadas no nível dos saberes. (MACHADO, 2006, p. 9).

O termo arqueologia foi constantemente usado por Foucault para distinguir a história que realizava da história das ideias, da epistemologia. Entretanto, devemos considerar que durante os estudos de Foucault o termo arqueologia sofreu modificações conceituais importantes e a cada livro que publicava era definido diferente (MACHADO, 2006, p. 13). Portanto, nesta forma mais profunda e radical tomada por Foucault há um percurso, uma construção do termo arqueologia que deve ser pensada para quando se falar em método arqueológico não se deve tomar como um número determinado de procedimentos invariáveis para a produção de conhecimento. 


\section{A ARQUEOLOGIA DO SABER}

A Arqueologia do Saber é uma obra de Foucault que tem como objetivo especificar um método de investigação que visa entender a ordem interna que constitui um determinado saber. Para Roberto Machado (2006), esta obra pode ser compreendida como desdobramento de três outras obras precedentes. A primeira é a História da Loucura, editada em 1961, em que Foucault descobriu a loucura como objeto em meio de uma miríade de discursos que permitiu seu surgimento. 0 processo de enclausuramento do louco pautado na moralidade permitiu uma percepção da loucura que se desdobrou em formulações de conhecimento e saber (FOUCAULT, 1997, p. 407).

A segunda obra é O Nascimento da Clínica, publicado em 1963, que deslocou o olhar sobre a doença mental para a própria doença, da psiquiatria para a medicina moderna a partir do século XIX. Deslocou o olhar de superfície para o olhar de profundidade que transformou o invisível em visível por meio de uma profunda investigação (MACHADO, 2006, p. 115). A terceira obra é As Palavras e As Coisas, de 1966, em que Foucault passou a se interessar pelas Ciências Humanas e tentou mostrar algumas mudanças - enquanto as ciências clássicas fixavam suas análises no nível das representações, as novas ciências fixavam no homem como objeto do conhecimento a ser desvendado.

Foucault, em A Arqueologia do Saber, rejeita as formas propostas pela história das ideias e sugere a discussão sobre as unidades discursivas. Primeiramente, Foucault propõe colocar em suspensão as aparentes unidades discursivas e se liberar para a busca de novas unidades discursivas que estariam invisíveis, que não seriam percebidas. Ele propõe, na verdade, 0 discurso como dispersão e o estudioso que se dedica a este trabalho deve elaborar uma descrição do que se encontra no discurso.

Para Foucault, as descrições devem buscar as regularidades que funcionam como leis de dispersão, isto é, formular regras capazes de reger a formação dos discursos. A busca dessas regras que disciplinam ob- jetos, tipos enunciativos, conceitos e temas que podem caracterizar o discurso como regularidade, situando aquilo que Foucault chama de formações discursivas.

\begin{abstract}
No caso em que se puder descrever, entre um certo número de enunciados, semelhante sistema de dispersão, e no caso em que entre os objetos, os tipos de enunciação, os conceitos, as escolhas temáticas, se puder definir uma regularidade (uma ordem, correlações, posições e funcionamentos, transformações), diremos, por convenção, que se trata de uma formação discursiva - evitando, assim, palavras demasiado carregadas de condições e consequências, inadequadas, aliás, para designar semelhante dispersão, tais como "ciência", ou "ideologia", ou "teoria", ou "domínio de objetividade”. (FOUCAULT, 2013, p. 47).
\end{abstract}

Em busca dessas regularidades que constituem 0 discurso, Foucault indica quatro níveis de regras de formação. A primeira regra é definir os objetos em um espaço comum; a segunda é identificar a formação das modalidades enunciativas; a terceira, na análise do discurso, é preciso estar sempre definindo as regras de formação dos conceitos; e, finalmente, a quarta regra é definir um sistema de relações entre diversas estratégias. Segundo Foucault, as relações entre objetos, tipos enunciativos, conceitos e estratégias possibilitam a passagem da dispersão à regularidade.

A análise arqueológica é uma descrição dos discursos que não deve ficar presa ao interno do próprio discurso, mas deve relacionar o evento discursivo com o acontecimento não discursivo. Em A Arqueologia do Saber, Foucault proporciona conceitos, categorias e ideias que possibilitam o caminho e pesquisa pela análise discursiva. 0 enunciado, a positividade, 0 arquivo são alguns conceitos fundamentais para o método arqueológico.

0 enunciado tem uma função enunciativa que permite que os signos e as regras se atualizem; deve-se tratá-lo na descontinuidade de que os liberta em todas as formas e no campo geral do discurso. Descrever enunciado é fixar vocabulários, definir as condições em que se realiza a função que deu uma série de signos, entender que ele não é oculto, mas também não é invisível. 
Um enunciado pertence a uma formação discursiva, como uma frase pertence a um texto, e uma proposição a conjunto dedutivo. Mas enquanto a regularidade de uma frase é definida pelas leis de uma língua, e a de uma proposição pelas leis de uma lógica, a regularidade dos enunciados é definida pela própria formação discursiva. A lei dos enunciados e o fato de pertencerem à formação discursiva constituem uma única e mesma coisa; o que não é paradoxal, já que a formação discursiva se caracteriza não por princípios de construção, mas por uma dispersão de fato, já que ela é para os enunciados, não uma condição de possibilidade, mas uma lei de coexistência, e já que os enunciados, em troca, não são elementos intercambiáveis, mas conjuntos caracterizados por sua modalidade de existência. (FOUCAULT, 2013, p. 142-143).

A análise enunciativa possui três traços característicos: busca estabelecer uma lei de raridade, trata os enunciados na forma sistemática da exterioridade e dirige-se às formas específicas de acúmulo e não de origem. Deve-se, portanto, descrever um conjunto de enunciado como uma figura lacunar e retalhada, como a dispersão de uma exterioridade e estabelecer o que Foucault chama de positividades (FOUCAULT, 2013, p. 153).

As positividades não caracterizam formas de conhecimento - quer sejam condições a priori e necessárias ou formas de racionalidade que puderam, por sua vez, ser empregadas pela história. Mas elas não definem, tampouco, o estado dos conhecimentos em um dado momento do tempo: não estabelecem o balanço do que, desde aquele momento, pôde ser demonstrado e assumir status de aquisição definitiva; o balanço do que, em compensação, era aceito sem prova nem demonstração suficiente, ou do que era admitido pela crença comum ou requerido pela força da imaginação. Analisar positividades é mostrar segundo que regras uma prática discursiva pode formar grupos de objetos, conjuntos de enunciações, jogos de conceitos, séries de escolhas teóricas. (FOUCAULT, 2013, p. 218).

A positividade desempenha um papel do que se poderia chamar um a priori histórico e não um a priori formal. $\mathrm{O}$ a priori histórico é um conjunto de regras que caracteriza uma prática discursiva; é na verdade, condição de realidade para enunciados, não condição de validade para juízos.
[...] o a priori não escapa à historicidade: não constitui, acima dos acontecimentos, e em um universo inalterável, uma estrutura intemporal; define-se como o conjunto das regras que caracterizam uma prática discursiva: ora essas regras não se impõem do exterior aos elementos que elas correlacionam; estão inseridas no que ligam; e, se não se modificam com o menor dentre eles, os modificam, e com eles se transformam em certos limiares decisivos. 0 a priori das positividades não é somente 0 sistema de uma dispersão temporal; ele próprio é um conjunto transformável. (FOUCAULT, 2013, p. 156).

Temos nas práticas discursivas sistemas que instauram os enunciados como acontecimentos e coisas. São todos esses sistemas de enunciado que proporcionam um arquivo, outro conceito precioso e caro ao historiador e fundamental para a teoria de Foucault.

0 arquivo é, de início, a lei do que pode ser dito, o sistema que rege o aparecimento dos enunciados como acontecimentos singulares. Mas o arquivo é, também, 0 que faz com que todas as coisas ditas não se acumulem indefinidamente em uma massa amorfa, não se inscrevam, tampouco, em uma linearidade sem ruptura e não desapareçam ao simples acaso de acidentes externos, mas que se agrupem em figuras distintas, se componham umas com as outras segundo relações múltiplas, se mantenham ou se esfumem segundo regularidades específicas [...]. (FOUCAULT, 2013, p. 158).

Essa concepção de arquivo em Foucault é diferente da forma clássica tratada pela historiografia. 0 arquivo não é o que protege o acontecimento do enunciado e conserva para as memórias futuras; é o sistema de sua enunciabilidade que não se registra numa linearidade progressiva e contínua, mas se inscreve nas singularidades do acontecimento, na ruptura e na descontinuidade. Foucault (2013, p. 160) ainda indica que a análise do arquivo:

“[...] comporta, pois uma região privilegiada: ao mesmo tempo próxima de nós, mas diferente de nossa atualidade, trata-se da orla do tempo que cerca nosso presente, que o domina e que o indica em sua alteridade; é aquilo que, fora de nós, nos delimita".

0 papel da arqueologia é, para Foucault, descrever os discursos como práticas caracterizadas no elemen- 
to do arquivo e interrogar o já dito no nível de sua existência. Assim, arquivo, positividade, enunciado e formações discursivas tornam-se instrumentos nas mãos daqueles que buscam uma arqueologia de um determinado saber e um conjunto metodológico poderoso para avaliar, a partir da função-autor, como culturalmente se constrói um determinado saber científico.

A proposta arqueológica de Foucault vem desde os anos 1970, gerando questionamentos principalmente dos estudiosos da história das ideias que pesquisaram, considerando a progressividade, linearidade e continuidade na evolução das ideias. Frente aos questionamentos Foucault faz, precisamente, uma comparação e diferenciação do que é arqueologia e história das ideias. Ele oferece um autoquestionamento que abre aos historiadores uma reflexão sobre a diferença entre história das ideias e arqueologia.

\begin{abstract}
No fundo, talvez eu não passe de um historiador das ideias, mas envergonhado ou, se quiserem, presunçoso. Um historiador das ideias que quis renovar inteiramente sua disciplina; que desejou, sem dúvida, dar-lhe o rigor que tantas outras descrições, bastante próximas, adquiriram recentemente; mas que, incapaz de modificar realmente a velha forma de análise, incapaz de fazer com que transpusesse o limiar da cientificidade (quer porque tal metamorfose jamais seja possível, quer porque não tenha tido forças para operar ele mesmo essa transformação), declara, para iludir, que sempre fez e quis fazer outra coisa [...] Eu não teria o direito de estar tranquilo enquanto não me separasse da "história das ideias", enquanto não mostrasse em que análise arqueológica se diferencia de suas descrições. (FOUCAULT, 2013, p. 166).
\end{abstract}

Para Foucault, a diferença entre análise arqueológica e história das ideias possui pontos de separação significativos que devem ser consideradas pelos historiadores. A arqueologia não busca definir pensamentos como na história das ideias; trata do discurso como documento, como signo de outra coisa, como documento-monumento. A arqueologia não busca a continuidade nos discursos, pelo contrário, busca defini-lo em sua especificidade. A arqueologia não quer reencontrar o ponto enigmático em que o indivíduo e o social se invertem um no outro.

\begin{abstract}
Finalmente, a arqueologia não procura reconstituir o que pôde ser pensado, desejado, visado, experimentado, almejado pelos homens no próprio instante em que proferiam o discurso; ela não se propõe a recolher esse núcleo fugidio onde autor e obra trocam de identidade; onde o pensamento permanece ainda o mais próximo de si, na forma ainda não alterada do mesmo, e onde a linguagem não se desenvolveu ainda na dispersão espacial e sucessiva do discurso [...] Não é nada além e nada diferente de uma reescrita: isto é, na forma mantida da exterioridade, uma transformação regulada do que já foi escrito. Não é o retorno ao próprio segredo da origem: é a descrição sistemática de um discurso-objeto. (FOUCAULT, 2013, p. 171).
\end{abstract}

Sem dúvida, a comparação entre história das ideias e arqueologia levaria a uma polêmica reflexão historiográfica que não caberia neste espaço, mas que, com certeza, abriria a novos problemas e indagações para dar continuidade aos estudos sobre as contribuições de Foucault para o campo da história.

Foucault propõe superar uma análise recorrencial que se faz apenas no interior de uma ciência constituída e formalizada, propõe uma análise histórica que se situa no limiar da cientificidade que interroga sobre a maneira como esse limiar pôde ser tratado a partir de figuras epistemológicas diversas. É a proposta de uma história arqueológica que sugere revelar as práticas discursivas no momento em que dão lugar a um saber que assume o status e o papel de ciência.

\begin{abstract}
Empreender nesse nível uma história das ciências não é descrever formações discursivas sem considerar estruturas epistemológicas; é mostrar como a instauração de uma ciência, e eventualmente sua passagem à formalização, pode ser encontrada sua possibilidade e sua incidência em uma formação discursiva e nas modificações de sua positividade [...] A análise das formações discursivas, das positividades e do saber, em suas relações com as figuras epistemológicas e as ciências, é o que se chamou para distingui-las das outras formas possíveis de história das ciências, a análise da episteme. (FOUCAULT, 2013, p. 229).
\end{abstract}

Essa proposta foucaultiana de descrever a episteme, conjunto de relações que podem ser descobertas, para uma determinada época, quando analisadas nas regularidades discursivas, permite compreender 
como se constrói um discurso. A análise da episteme permite compreender o jogo das coações e das limitações que, em um momento determinado, se impõem ao discurso.

\section{CONSIDERAÇ̃̃ES FINAIS}

Neste estudo, apresentou-se de forma introdutória alguns conceitos discutidos por Foucault em sua obra A Arqueologia do Saber como um primeiro passo metodológico para perscrutar e escandir um discurso. Vale frisar que o método arqueológico relaciona-se às análises de tipo científico ou às teorias que respondem a critérios de rigor.

A proposta defendida por Foucault em sua obra A Arqueologia do Saber dá lastro para análise da construção de um discurso, desde que não se torne um a priori formal, isto é, uma camisa de força que impossibilite identificar as particularidades ou as próprias regularidades de um objeto de pesquisa, mas se torne uma possibilidade, uma orientação, um parâmetro para a análise do discurso científico.

0 peculiar da proposta foucaultiana é o questionamento a respeito da ciência, assim como da ideia de episteme. Foucault deixa claro em A Arqueologia do Saber que a arqueologia não é uma ciência - a qual procura propor fundamentos de uma ciência futura - a palavra arqueologia designa somente uma das linhas de abordagem para a análise das performances verbais, isto é, dos discursos.

\section{REFERÊNCIAS}

BRANDÃO, H.H.N. Introdução à análise do discurso.

3.ed. rev. Campinas: Unicamp, 2012.

CHARTIER, R. Autoria e história cultural da ciência. Priscilla Faulhaber, José Sérgio Leite Lopes (Org.). Rio de Janeiro: Beco do Azougue, 2012.

\section{FOUCAULT, M. A história da loucura na idade clássica.} São Paulo: Perspectiva, 1997.

FOUCAULT, M. A arqueologia do saber. Trad. Luiz Felipe Baeta Neves. 8.ed. Rio de Janeiro: Forense Universitária, 2013.

GIACOMINI, M.P.; VARGAS, A.Z. Foucault, a Arqueologia do Saber e a Formação Discursiva. Veredas On Line - Análise do Discurso, Juiz de Fora, fev. 2010. PPG Linguística/UFJF. Disponível em: <http://www.ufjf.br/revistaveredas/files/2010/04/ artigo-09.pdf>. Acesso em: 16 ago. 2017.

MACHADO, R. A ciência e o saber - a trajetória da arqueologia de Foucault. Rio de Janeiro: Jorge Zahar, 2006.

RAGUSA, Pedro. Arqueologia do saber e a história. V Congresso Internacional de História. Universidade Estadual de Maringá. Set. 2011. Disponível em: <http://www.cih.uem.br/anais/2011/trabalhos/243. pdf>. Acesso em: 16 ago. 2017.

VEYNE, Paul. Como se escreve a história - Foucault Revoluciona a História. 2.ed. Brasília: São Paulo: EDUNB, 1982. 